\title{
Recognition of the Incorrect Values of Measured Parameters at Nuclear Power Plant Operation in Stationary Modes
}

\section{G. V. Chichikin, S. T. Leskin, and A. Y. Puzakov}

Obninsk Institute for Nuclear Power Engineering of the National Research Nuclear University MEPhl, Studgorodok 1, Obninsk, Kaluga region, 249040, Russia

\section{Abstract}

In this paper, we consider a variant of solving the problem of recognizing incorrect values of the measured parameters on the power unit of a nuclear power station (NPP) using methods of the theory recognition of images. As initial data, the measured parameters of the primary circuit of a VVER NPP in cold and hot operating conditions are used. The analysis of the data structure and localization of the images of the

Corresponding Author:

G. V. Chichikin

sir.joeyfa@yandex.ru

Received: 23 December 2017

Accepted: 15 January 2018

Published: 21 February 2018

Publishing services provided by Knowledge $\mathrm{E}$

(c) G. V. Chichikin et al. This article is distributed under the terms of the

Attribution License, which permits unrestricted use and redistribution provided that the original author and source are credited.

Selection and Peer-review under the responsibility of the AtomFuture Conference Committee.

\section{G OPEN ACCESS} states of the nuclear island is carried out in the two-dimensional space of the principal components. To classify the input data a decision rule is used $d_{i}(x)-d_{j}(x)>0$. Individual measurements that do not fall into any of the classes are most likely to be attributed to incorrect value.

Keywords: recognition of images, exploratory data analysis, method of principal components, k-means algorithm, clustering, perceptron algorithm, discriminant analysis, classification problem, VVER.

\section{INTRODUCTION}

Today, 35 power units with installed capacity of 27.9 GW are operated in Russia, 18 of them with VVER reactors (12 of them with VVER-1000, 1 with VVER-1200, and 5 with VVER-440 of various modifications) specified in [1].

Experience of accidents and incidents at nuclear power plants shows that almost all accidents could be prevented by operators with timely recognition of the situation by analyzing the signals of instrumentation. Not the least role in the analysis of the state of the equipment is the evaluation of the reliability of the data [2-3].

The purposes of the work: perform an exploratory analysis of the values of the parameters of the main equipment of the primary circuit while the VVER unit is in hot and cold operating states, and testing the hypothesis of the possibility of recognizing in these states incorrect values by image recognition methods. 
The solution of the tasks is based on the methodology recognition of images, cluster and discriminant analysis.

The article presents the results of the analysis of the cold and hot states of the power unit. The actual data is used as initial data. They are classified according to the stationary operating conditions of the power unit of the nuclear power plant.

\section{INITIAL DATA}

When a nuclear power unit operates in one of the stationary modes, then the parameters of the main equipment of the primary circuit are stabilized [4]. These parameters are presented in Table 1 . Since the primary circuit is a bound and closed system without shut-off valves on hot and cold loops, then the operating modes of the loops is the same. For this reason, the exploratory data analysis uses the average values of the coolant parameters for all loops of the primary circuit.

\section{REDUCTION IN THE DIMENSION OF INITIAL DATA}

For each parameter from Table 1, a data set (sample) with a volume of 60 values is selected, which is also a time series, which within an hour should remain stationary. For each such sample, in the hot and cold operating state, statistical processing of data is performed.

Preliminary processing of data includes the exclusion of outlying case. For this purpose, the Irwin criterion is used [5]:

$$
\lambda=\frac{x_{i+1}-x_{i}}{S}
$$

$x_{i}, x_{i+1}$-current and following value of the parameter;

$S$ - standard deviation of values from the median $\bar{X}_{M}$;

$n$ - sample size.

On condition $\lambda>\lambda_{q}$ the value of the parameter $x_{i}$ is the outlying case. $\lambda_{q}$ - critical value of the coefficient at significance level $q$. In this paper, it is customary $\lambda_{q}=1.1$ at $q=0.05$ and $n=60$. After exclusion of outlying case, the values $\bar{X}_{M} u S$ of those samples in which they were detected are corrected.

The next step is to determine and exclude the trend of the time series for each sample. To check for stationarity of the time series is used the property of the coefficient of autocorrelation dependence from time $\Delta \mathrm{T}[6,7]$. 
TABLE 1: Parameters that represent the operation of the main equipment of the primary circuit of the nuclear power plant.

\begin{tabular}{|c|c|c|c|c|}
\hline № & Parameter name & Notation & $\begin{array}{l}\text { Measurement } \\
\text { range }\end{array}$ & Units \\
\hline 1 & Pressure above the core & $P_{\text {core }}$ & $0-25$ & $\mathrm{MPa}$ \\
\hline 2 & $\begin{array}{l}\text { Average temperature of coolant in } \\
\text { hot loops }\end{array}$ & $T_{\text {hot }}$ & $0-400$ & ${ }^{\circ} \mathrm{C}$ \\
\hline 3 & $\begin{array}{l}\text { Average temperature of coolant in } \\
\text { cold loops }\end{array}$ & $T_{\text {cold }}$ & $0-400$ & ${ }^{\circ} \mathrm{C}$ \\
\hline 4 & Total flow of coolant through loops & $F$ & - & $\mathrm{m}^{3} / \mathrm{h}$ \\
\hline 5 & $\begin{array}{l}\text { Pressure inside the pressure } \\
\text { compensator }\end{array}$ & $P_{\text {compensator }}$ & $0-25$ & $\mathrm{MPa}$ \\
\hline 6 & $\begin{array}{l}\text { Coolant temperature in the pressure } \\
\text { compensator }\end{array}$ & $T_{\text {compensator }}$ & $0-400$ & ${ }^{\circ} \mathrm{C}$ \\
\hline 7 & $\begin{array}{l}\text { Coolant level in the pressure } \\
\text { compensator }\end{array}$ & $L_{\text {compensator }}$ & $1.43-15.03$ & $\mathrm{~m}$ \\
\hline 8 & $\begin{array}{l}\text { The average pressure of the hot } \\
\text { steam at the outlet of the steam } \\
\text { generator }\end{array}$ & $P_{\text {steam }}$ & $0-10$ & $\mathrm{MPa}$ \\
\hline 9 & $\begin{array}{l}\text { The average temperature of the hot } \\
\text { steam at the outlet of the steam } \\
\text { generator }\end{array}$ & $T_{\text {steam }}$ & $0-300$ & ${ }^{\circ} \mathrm{C}$ \\
\hline 10 & $\begin{array}{l}\text { The average temperature of the } \\
\text { feedwater at the inlet steam } \\
\text { generator }\end{array}$ & $T_{\text {feedwater }}$ & $0-400$ & ${ }^{\circ} \mathrm{C}$ \\
\hline 11 & $\begin{array}{l}\text { The average level of the feedwater at } \\
\text { the steam generator }\end{array}$ & $L_{\text {feedwater }}$ & $1.69-3.29$ & $\mathrm{~m}$ \\
\hline
\end{tabular}

Thus, all processes can be considered stationary after data processing. To identify the individual conditions of the power unit equipment, the initial data sampling was supplemented by measurements up to four hours of operation of the power unit in the cold and hot states.

For a visual representation of the data structure, we reduced the dimension of the initial parameter space using the method of principal components, which allows [8]:

- remove poorly informative signs;

- remove multicollinearity;

- reduce the number of parameters considered from 11 to 2 in the space of principal components for better interpretation;

- find what parameters determine the operational state of the power unit at different times. 
The initial data were centered and normalized:

$$
x_{i j}^{*}=\frac{x_{i j}-\bar{X}_{M, j}}{S j},
$$

$x_{i j}$ - the $i$ measurement of the parameter $j$;

$S_{j}$ - standard deviation of the parameter $j ;$

i-measurement number;

$j$ - parameter number.

This step is necessary, because the selected parameters have different nature and units of measurement.

The next step is to determine the correlation matrix $R_{x i x j}$ for the cold and hot state of the power unit, which consists of correlation coefficients $r_{x i x j}$ parameters. Next, we find the eigenvalues $\lambda_{\text {cold }}$ and $\lambda_{\text {hot }}$ for each correlation matrix from an equation of the form [9]:

$$
R_{x i x j} \phi_{j}=\lambda_{j} \phi_{j}{ }^{\prime},
$$

$\lambda_{j}$ - eigenvalues of the correlation matrix $R_{x i x j}$;

$\phi_{j}$ - the basic vector, which is the orthonormal eigenvector of the correlation matrix $R_{x i x j}$, corresponding to the $j$ eigenvalue.

Next, we define the orthonormal eigenvectors of the correlation matrix $R_{x i x j}$, which are the weighting coefficients for the principal components. To visualize the various states of the power unit, the initial parameter space (Table 1) was projected into two eigenvectors with maximum eigenvalues, while preserving up to $80 \%$ of the sample variance of the original data. The projections of the initial data space into eigenvectors are shown in Fig. 1. One can see from them that the separation operational states of the nuclear island are represented by non-overlapping sets, namely, classes.

\section{CLUSTER ANALYSIS}

To formalize the process of separation into classes, a non-hierarchical method of kmeans was used. This method seeks to minimize the total root-mean-square deviation at all points of each cluster. This quality score determines the total sum of squares of deviations in the characteristics of all images, entering a certain cluster, from the corresponding average values for the cluster. At each iteration, a new centroid is calculated for each cluster obtained in the previous step, and then the vectors are divided into clusters again according to which of the new centers is closer to the selected metric. The algorithm is completed when no iteration of clusters occurs at 
any iteration $[10,11]$. The results of the algorithm for each of the operational states are presented in the table 2.

TABLE 2: Characteristics of clusters for cold and hot operational states.

\begin{tabular}{|c|c|c|c|c|c|}
\hline $\begin{array}{l}\text { Operational } \\
\text { state of the } \\
\text { power unit }\end{array}$ & $\begin{array}{l}\text { Cluster } \\
\text { number }\end{array}$ & $\begin{array}{c}\text { The sum of } \\
\text { quadratic } \\
\text { errors }\end{array}$ & Standard deviation & $\begin{array}{l}\text { Cluster } \\
\text { radius }\end{array}$ & Metrics \\
\hline \multirow[t]{4}{*}{ Cold } & 1 & 5.383 & 0.119 & 0.622 & Euclid \\
\hline & 2 & 4.760 & 0.128 & 0.513 & \\
\hline & 3 & 4.325 & 0.153 & 0.847 & \\
\hline & 4 & 4.201 & 0.148 & 0.695 & \\
\hline \multirow[t]{4}{*}{ Hot } & 1 & 1.293 & 0.063 & 0.305 & \\
\hline & 2 & 2.465 & 0.109 & 0.436 & \\
\hline & 3 & 4.617 & 0.147 & 0.632 & \\
\hline & 4 & 3.567 & 0.109 & 0.498 & \\
\hline
\end{tabular}

Controversial clusters have not been found in all operational states, because clusters are distant enough from each other.

\section{DISCRIMINANT ANALYSIS AND THE CREATION OF CLASSIFIERS}

To create a classifier, the initial sample is divided by volume in a ratio of 2 to 3 into two samples: a training sample and a test sample [8].

On the training set, the decision rules $d(\mathbf{x})$ are constructed, representing 4 linear functions equal to the number of classes in each of the operational states [11]:

$$
d(x)=w^{\prime} x,
$$

$x=\left(P C A_{1}, P C A_{2}, 1\right)^{\prime}$ - augment image vector;

$w=\left(w_{1}, w_{2}, w_{3}\right)$ - augment weight vector.

Further, to find the weight vector, we use the generalized perceptron algorithm with error correction, working according to the following algorithm [11]:

There are 4 classes $\omega_{1}, \omega_{2}, \omega_{3}, \omega_{4}$ and at the $k$-th step of the iteration of the learning procedure, the image $x(k) \in \omega_{j}$ is presented to the system. In this case, 4 decision functions are calculated:

$$
d_{j}[x(k)]=w_{j}(k) x(k),
$$



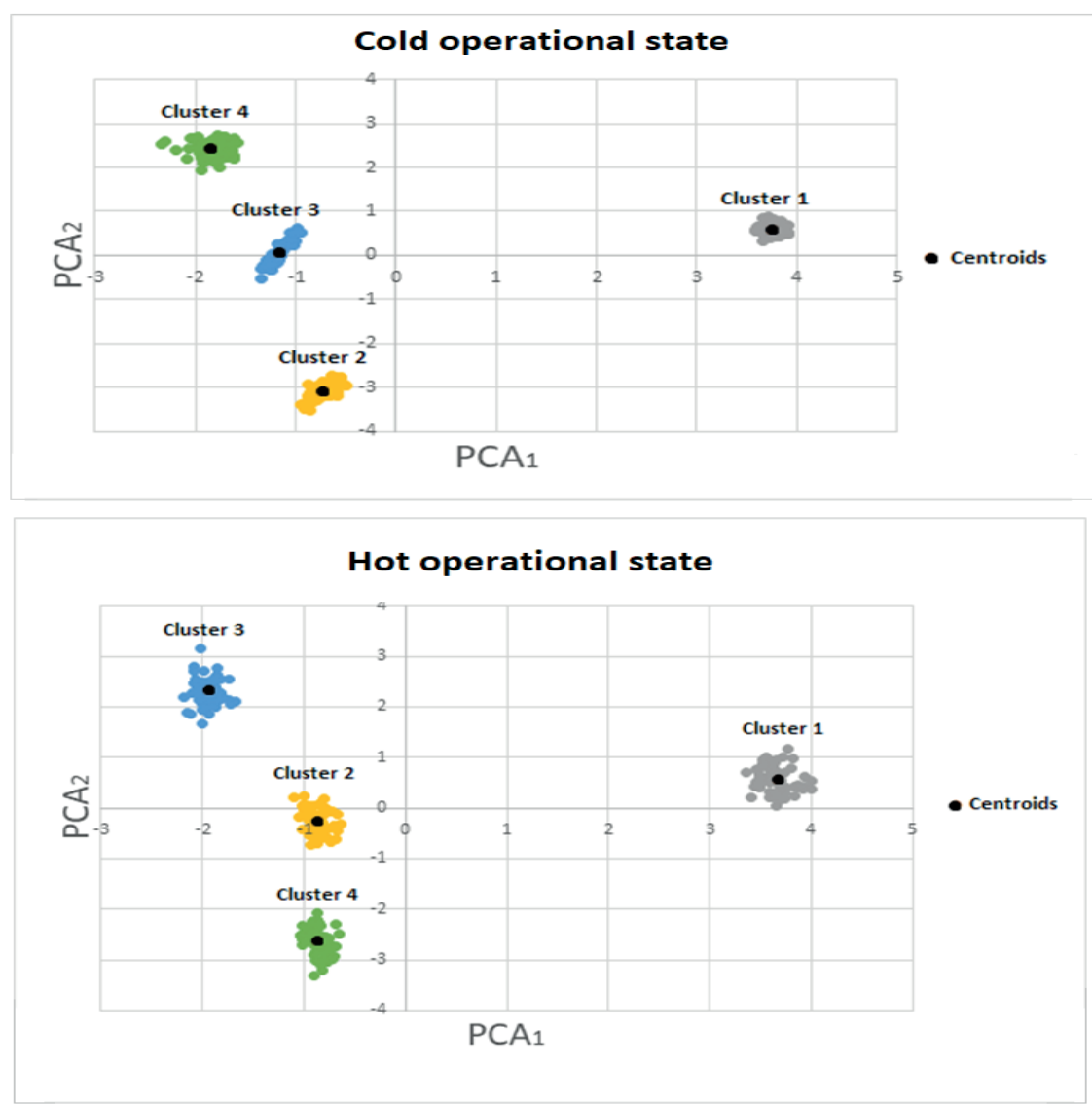

Figure 1: Cold and hot state clusters in the space of principal components.

If the conditions $d_{i}[x(k)]>d_{j}[x(k)]$ are met for all $\mathrm{j} \neq \mathrm{i}$, then the weights do not change:

$$
w_{j}(k+1)=w_{j}(k),
$$

If the condition $d_{i}[x(k)] \leq d_{L}[x(k)]$ is satisfied from some L-step, then the correction of the weights:

$$
\left\{\begin{array}{c}
w_{i}(k+1)=w_{i}(k)+c \cdot x(k) \\
w_{L}(k+1)=w_{L}(k)-c \cdot x(k) \\
w_{j}(k+1)=w_{j}(k)
\end{array}\right.
$$

c - positive constant.

After finding the type of decision functions, the definition of the separation boundaries:

$$
d_{i}(x)-d_{j}(x)=0
$$

$i, j=[1,4]$ for all $i \neq j$.

The final form of the separation boundaries for the cold and hot states is shown in Fig. 2 (a, b). 


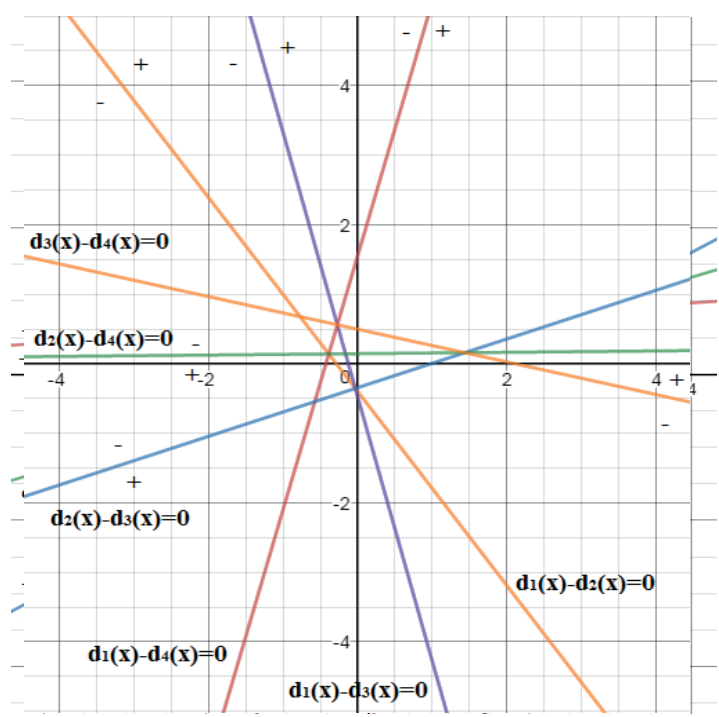

(a)

(b)

Figure 2: Separating boundaries in the space of principal components for cold (a) and hot (b) operational states.

At the final stage, decisive rules are defined

$$
d_{i}(x)-d_{j}(x)>0
$$

$i, j=[1,4]$ for all $i \neq j$.

This means that the recognizable image is checked by the whole set of inequalities and, depending on the characters it receives, it is determined in the region corresponding to one of the four classes. Then they were tested. All images from the test sample were classified correctly in all operational states.

\section{RECOGNIZING OF THE INCORRECT VALUES}

In the recognition mode, the classifier is fed with unknown images. Depending on the set of signs of decisive rules received, the new image is determined in the corresponding area that was obtained in the learning stage.

To simulate incorrect values of the measured parameter, a sample was selected from the initial set of values of the hot state of the parameter of the average feed water temperature at the inlet to the steam generator. This parameter is important, because it is used in calculation of reactor power and it influence on the accuracy of the definition. Characteristics of the sample: the volume is 60 values, there are no outlying case, the time series is stationary. New data has also been transferred to the space of the principal components. The recognition result is shown in Fig. 3. 


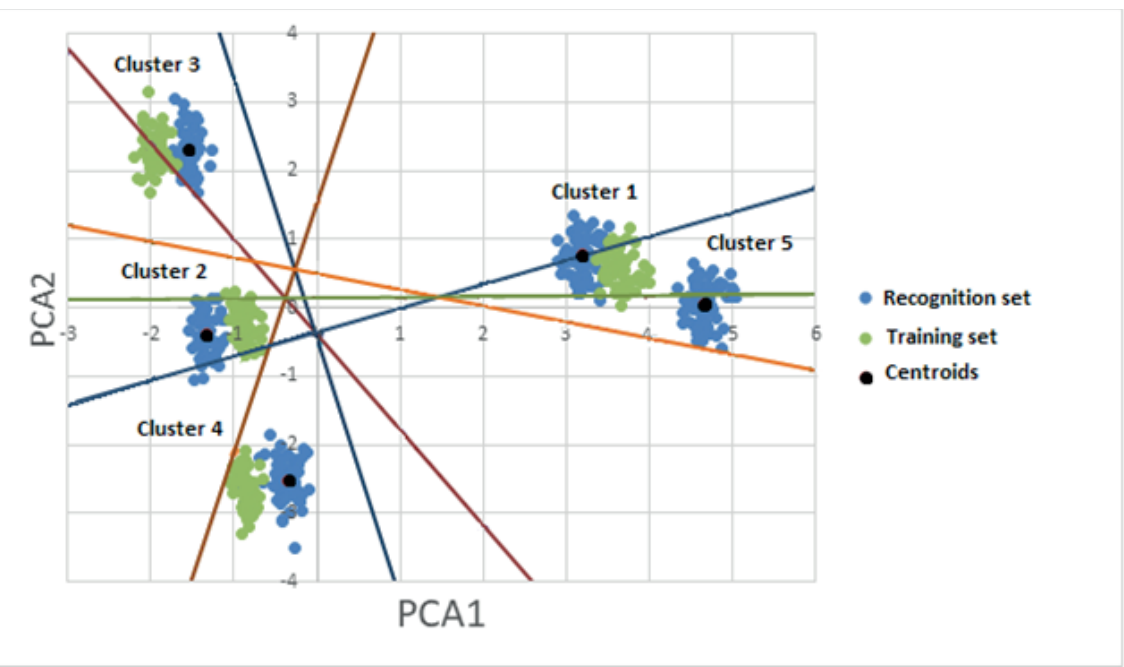

Figure 3: Recognition of incorrect values of the average feed water temperature at the inlet to the steam generator.

From the scattering diagram of the images, the new sample formed a cluster different in position from all the others, but similar in form to cluster 1. The classifier defined a new sample to class 1 , because the signs of the first three dividing borders turned out to be positive. Cluster analysis of recognizable images was also carried out using the k-means method. The results of cluster analysis showed that cluster 5 is a distance from the nearest cluster 1 by a distance exceeding the radius of any one of them. This means that a new set containing incorrect values was recognized as a different state that was not included in the training set.

\section{CONLUSIONS}

As a result of this work, the technique and algorithms for recognizing the states of the nuclear island have been developed, and also unreliable data of the measuring system. During it preliminary results of processing of operational data of hot and cold states of the power unit, which showed the prospect of further use of the proposed approach for the identification and analysis of the state of the power unit.

\section{References}

[1] Nuclear power plants in Russia. Date views 23.09.2017 www.rosenergoatom.ru/ stations_projects/atomnye-elektrostantsii-rossii/ 
[2] S. T. Leskin, Razrabotka algoritmov raspoznavaniya anomalii v sostoyanii oborudovaniya AES po analizu dannyh operativnogo tekhnologicheskogo kontrolya.//Izvestiya vuzov. Yadernaya energetika. - 1997. - \#4. - pp. 4-12. (in Russian)

[3] S. T. Leskin, V.I. Slobodchuk, A.S. Shelegov. Analiz sostoyaniya GCN VVER-1000 v processe expluatacii.//Izvestiya vuzov. Yadernaya energetika. - 2016. - \#4. - pp. 12-23. (in Russian)

[4] R. P. Baklushin. Expluatacionnie regimi AES: uchebnoe posobie - 2-e izd., pererab. i dop. M.: Izdatelskiy dom MEl, 2012 pp: 532 c. (in Russian)

[5] L. N. Tretiyak. Obrabotka rezultatov nabludenii: uchebnoe posobie. - Orenburg: GOU OGU, 2004. - 171 c. (in Russian)

[6] U. E. Voskoboinikov. Ekonometrika v EXCEL. Chast 2. Analiz vremennih ryadov. Uchebnoe posobie. - NGASU, 2008. - 155 C. (in Russian)

[7] B. V. Gnedenko. Kurs teorii veroyatnostei. Uchebnik. Izd. 8-e, ispr. I dop. - M.:Editorial URSS, 2005. Pp: 448 (in Russian)

[8] S.A. Aivazyan, V.M. Buchstaber, I.S. Yenyukov, L.D. Meshalkin. Applied statistics. Classification and reduction of dimensionality. Reference edition. Finansy I statistika. Moscow 1989. Pp: 607.

[9] V. A. Il'in, E. G. Poznyak. Linejnaya algebra: Ucheb.: Dlya vuzov. - 5-e izd. - M.: Fizmatlit, 2002. - pp: 320 (in Russian)

[10] I. D. Mandel. Klastenii analiz. - M.: Finansy I statistika, 1988. - pp: 176. (in Russian)

[11] J. T. Tou, R. Gonzalez. Pattern recognition principles. Addson - Wesley Publishing Company 1974, pp: 404. 